\title{
Psychopathy: Simple or Syndromal Disorder of Personality
}

\author{
Vito Zepinic ${ }^{1}$ \\ ${ }^{1}$ PsychClinic P/L, London, United Kingdom \\ Correspondence: Vito Zepinic, PsychClinic P/L, London, United Kingdom. E-mail: vito@psychclinic.net
}

Received: August 31, 2017

Accepted: September 5, 2017 Online Published: September 12, 2017

doi:10.5539/ijps.v9n4p1

URL: http://doi.org/10.5539/ijps.v9n4p1

\begin{abstract}
Psychopathy is one of the most puzzling clinical diagnosis and has been a subject to numerous theoretical attempts to define this personality disorder. Although not being recognised as an independent disorder in the DSM-5, the disorder is manifested in different areas of the individual's personality and subsequently became subject of consideration as syndromal, not a simple disorder. This condition is usually stable and long-lasting, its onset usually traced back to childhood or adolescence, often being undiagnosed and/or successfully masked by the psychopath. Some psychopaths are quite successful in their profession, others are commonly related to the violence or crime.
\end{abstract}

Keywords: attachment, criminality, personality disorder, psychopathy, stress, syndromal disorder

\section{Introduction}

As disordered personality, psychopathy became a subject of interest in psychiatry and psychology, but also in law, philosophy and criminology (Zepinic, 2017). Controversies in defining psychopathy is evident since the first theoretical and clinical evaluation by American psychiatrist Cleckley (1941), and then Hare (1970), Patrick (2006), and others. However, confusion about psychopathy does not only appeared in regard to its definition and reliable assessment but with regards of treatment too. Furthermore, the differences and similarities in defining psychopathy and antisocial personality require more research in making distinction while focusing on interpersonal and affective symptoms (e.g., callousness, grandiosity, lack of empathy, deceitfulness) that lead to the over-diagnosis of the psychopathy in the criminal populations and under-diagnosis in non-criminal psychopaths (Zepinic, 2017; Hare, 1970).

Additionally, the clinicians (Benjamin, 2003; Cooke et al., 1998; Gao \& Reine, 2010; Hakkanen-Nyholm \& Nyholm, 2012; Zepinic, 2010, 2017) suggest that confusion about relationship between the psychopathy and the personality disorders arising from the fact that psychopath, sociopath, and antisocial personality have been defined by a multitude of their different and confusion attitudes. Regardless of evident differences between these conditions, the clinicians are agreed that antisocial behaviour might be result of the appreciably different personality combinations. However, while psychopathy has similarities to the antisocial (asocial) personality disorder and criminal behaviour, it should be not confused with the criminal behaviours in general (Babiak \& Hare, 2006; Babiak et al., 2010; Gao \& Reine, 2010; Newman \& Kosson, 1986; Porter et al., 2009; Zepinic, 2017a). Antisocial or criminal behaviours in psychopaths are motivated by different factors than is that of non-psychopaths, and topography of the criminal conduct is also different (Hare, 1999; Zepinic, 2017).

Psychopathy cannot be synonymous with criminality or violence, nor all psychopaths are inevitable engage in the criminal activities, and not all criminals are the psychopaths (Cleckley, 1941; Patrick, 2006; Zepinic, 2017). Moreover, many psychopaths are quite successful in their professions (politicians, managers, public authorities, lawyers, etc.) and have never had any offence of law. However, perhaps more research should offer evidence that the successful psychopaths are not very different from their incarcerated counterparts in terms of pathological personality traits but rather to their ability to deal with their pathology and mask the inner impulses. Hare (1999) defined psychopathy as a clinical construct traditionally defined by a constellation of interpersonal affective, and lifestyle characteristics. However, despite numerous researchers there is still no full agreement among the theorists and the clinicians about the aetiology and therapy of psychopathy. In general, the criteria to define psychopathy is usually related to the history of irritability, hostility, and aggression, including overt physical violence. 


\section{Psychopathy and Personality Disorders}

\subsection{Early Traumatisation and Personality Disorders}

Personality disorders have been defined as an enduring pattern of inner experience and behaviour that deviates markedly the individual's personality structure and that this pattern has to be manifested in areas of cognition, affect, interpersonal functioning and impulse control. The pattern of disorder must be flexible and pervasive across a broad range of personal and social situations, and leads the individual to a significant distress or impairment in social, occupational, or other important areas of functioning (APA, 2013). Personality disorder is usually stable and long-lasting condition, and its onset traced back to the early childhood or adolescence. By definition, the features of personality disorder must not be better accounted for as a manifestation or consequences of another mental disorder despite overlap in symptoms, nor due to physiological effect of substance abuse or a general medical condition.

Sarkar and Adshead (2006) are of opinion that the personality disorders are an aftermath of the disorganised attachment and affect regulation. Affects are a driving force to assist or select person in goal-directed behaviours helping in finding sources of energy, to deal with external obnoxious agents and maintains social relationship to support a life-sustaining homeostasis. To achieve these goals, it should exist a harmony and interplay among multiple systems: endocrine, immune, drives and motivations, approach and avoidance behaviours. This is quite complex interplay and no simple isolated system could bring an optimal homeostasis (psychological equilibrium) Thus, people instinctively or purposely make and maintain different types of social relationships which are function of them, their complexity, and inter or intrapersonal attachments. As such, the interpersonal affective responses need to be regulated and organised in order to be effective and constructive. Affect regulation in any optimal homeostatic system means not only initiating a response to a stimulus, which itself should be organised and effective, but also modulating it appropriately and turning it off when no longer required.

Based on a research into the neural development of the infant brain, Schore (2003) has set out an explanatory framework of the affects regulation. He was of opinion that secure attachment through the human interactions foster identification of affects, the response to them, and the regulation of the affective system which regulates development of the personality. Alongside with the importance of one's genetic personality traits, many researchers of the early personality development suggest that affects regulation and secure attachments are protective and generate personality nature.

Some authors (Allport, 1961; Benjamin, 2003; Black \& Larsen, 1999; Meloy, 1988; Raine, 2013; van der Hart et al., 2006; Zanarini et al., 2000; Zuckerman, 2005) found that a high prevalence of the early traumatisation and insecure attachment frequently cause development of the psychopathic personality. As it is described in DSM-5 criteria (APA, 2013), the classic vision of psychological trauma considers that the trauma event(s) and its characteristics had been a threat to the physical and/or psychological integrity to oneself or other people. However, in childhood many perceived threats are more from the caregivers' affective signals and caregivers' ability than from the actual level or physical danger or risk.

Many clinicians called early traumatisation "hidden trauma" which consequences to appear lately in different forms of dysfunctions including a disordered personality structure (Zepinic, 2011). In case of the caregivers' inability to modulate secure attachment and affects regulation with a child, will cause the comorbidity between the early traumatisation and personality dysfunctions, leading to development of the psychopathic personality. This is in particular if caregivers' relationship has been characterised by an emotional abuse which possible will generate one's development of the personality offences. History of the childhood trauma and poor attachment predict poor outcome-trauma symptoms together with the dissociative symptomatology contribute to self-destructive behaviour.

Developmental trauma indicates than an insecure attachment often causes a development of the dysfunctional psychopathic personality. An emotional neglect and insecure attachment cause powerful traumatisation and then development of the psychopathy. Numerous studies found that children who had at least one supportive parent or caretaker have less risk or vulnerability to develop dysfunctional (pathological) personality. Proper parental bonding is a major factor that has been believed to be associated with the development of normal personality, but those patients who reported one or both parents as less carrying indicates that the control without affection or emotional bonding had contributed to the development of the psychopathic personality.

Abusive or neglectful parental behaviours may cause not only development of the psychopathic personality but also increase vulnerability to other mental health disorders. Zanarini et al. (2000) had reported that female patients, who recalled their mother as neglectful and father as abusive, were more likely to have been sexually abused by a non-caretaker. They hypothesised that a neglectful mother not being able to protect the child from 
sexual abuse by a non-caretaker and an abusive father might lead his daughter to believe that being used or abused is unavoidable.

Dysfunctional attachment relates to a lack of integrated self schemata (self-coherence and self-continuity) which suggests that early experience of the disordered relatedness and attachment could be predisposition for development of psychopathic personality. Benjamin (2003) suggested that pathological experience of the interpersonal attack, neglect and threat of abandonment in childhood may account for the adult person's perception of relationships as aggressive and neglectful. Disorganised attachment in childhood makes individual deeply ambivalent and fearful of close relationships, and could be predisposing to abusive in adulthood.

Having fear of being rejected or ignored can unleash very intense emotional reactions and such patients can react in many different ways in the face of losses - it is not that they developed dependency-style relationships - these features can be understood from the intense fear that their early traumatic memories and trauma experiences can be triggered. If the individual has had an attachment figure who was neglectful or violent, the need for secure attachment could be extreme, and when psychopathic personality is faced with the possibility of losing secure attachment figure, the emergency urges appeared as "do not leave me". However, in insecure early attachment, defensive action systems could be activated in adult time with a fight of the apparently "normal part" of the personality which, in fact, does not have self-perspective "if you leave me I will kill myself".

Zanarini et al. (2000) reviewed the empirical literature that described estimates of childhood sexual abuse in borderline personality disorder between $40-70 \%$ compared with the rate of childhood sexual abuse in other DSM-5 Axis II disordered patients (19-26\%). The study revealed a significant relationship between a sexual abuse and childhood maltreatment which lead to the development not only of the psychopathic personality, but to other mental disorders too. Affects dysregulation and poor attachment in the early development cause a significant impairment in self (identity or self directions), and interpersonal (empathy and intimacy) functioning -impairments which are relatively enduring across time and consistent across situations. Battle et al. (2004) in multisite study assessing 600 patients diagnosed with the personality disorders, found that rates of the childhood maltreatment was high ( $73 \%$ of the patients reported abuse and $82 \%$ reported neglect). Borderline personality disorder has been more associated with the childhood abuse and neglect than other personality disorders.

\subsection{Overlap of Symptoms in Psychopathy and Personality Disorders}

As it was stated earlier, overlap in symptoms of psychopathy and personality disorders is common, in particular with antisocial and narcissistic personality disorders. According to DSM-5 criteria (APA, 2013), the symptoms of borderline personality disorder overlaps with the symptomatology that is often found in psychopathy: (1) significant impairment in personality functioning characterised by (a) identity (impoverished, poorly developed, or unstable self-image, dissociative states under pressure), (b) self direction (instability in goals, aspiration, or career plans); and (2) the impairments in interpersonal functioning which is marked by (a) empathy (compromised or no ability to recognise the feelings and needs of others, perceptions of others selectively biased toward negative attributes or vulnerability), (b) intimacy (intense, unstable, and conflicted relationships, marked by mistrust, neediness, and anxious preoccupation with a real or imagined abandonment, close relationships are often viewed in extremes of idealisation and devaluation and alternating between over-involvement and withdrawal).

Further, in borderline personality disorder the pathological personality traits are marked by (1) negative affectivity in form of (a) emotional liability (unstable emotional experience and frequent mood changes, emotions that are easily aroused, intense, and/or out of proportion to events and circumstances), and (b) separation insecurity (fears of rejection by -and/or separation from- significant others, associated with fears of excessive dependency and complete loss of autonomy); and (2) disinhibition characterised by (a) impulsivity (acting out the spur of the moment in response to immediate stimuli, acting out on a momentary basis without the plan or consideration of outcomes, difficulty establishing or following plans, sense of urgency and self-harming behaviours under an emotional distress), (b) risk-taking (engagement in dangerous, risky, and potentially damaging activities, unnecessarily and without regard to consequences, lack of concern for one's limitations and denial of the reality of personal danger); (3) antagonism characterised by (a) hostility (persistent or frequent angry feelings, anger or irritability in response to minor sights and insults).

Psychopaths are known for maintaining interpersonal relations volatile and problematic. Certainly, it is hard to understand how statement like "leave me alone" can really mean "please do not leave me, I need you". This jigsaw could be explained by the psychopath's unawareness of his lack of a proper connection between "feel and need" being also confused by the reactions he gets from others. As psychopath needs "loyalty and glorification", especially when he perceives a "special connection", he will feel valued if others recognise his "special 
personality" which in fact is quite dysfunctional, but well hidden by the psychopath (Patrick, 2006; Zepinic, 2017).

Frequently, when psychopath finds his "desired attachment", he filters the negative aspects of his self-constructing an idealised figure. When these negative aspects became undeniable (e.g., during violence or physical/verbal abuse of the attachment figure) different defensive action system could be simultaneously activated and block appearance of "hidden secrets" of dysfunctional personality. Thus, the psychopath's perceptions and actions toward the significant others will differ then toward the ordinary ones, including idealisation from those from whom the psychopath required glorification for his "unique" personality (Zepinic, 2017).

Because of his fear of avoidance, the psychopath activates the flight defensive mechanism in order to keep dysfunctional personality unmasked. However, any trigger may cause a profound sense of the betrayal and insecure attachment as it was experienced earlier. The trigger event can be a reminiscence of very relevant details for the current attachment. That is, the apparent disproportion in emotional reaction in fact is not related to "here-and-now" circumstances but to memories of the traumatised attachment. In other words, the patient lives and reacts in trauma time (van der Hart et al., 2006; Zepinic, 2012) and hostile attitudes are not against the current attachment figure. In the individual with an early traumatisation, any high tone of voice or critical comment may trigger an unjustified negative reaction. The person's disorganisation may be the outward manifestation of competition among rigidly organised dissociative parts during early traumatisation and current defence and attachment systems.

Some clinicians (van der Kolk et al., 1996; Zepinic, 2017a) remarked that diagnostic criteria for posttraumatic stress disorder do not include relevant features of personality changes that can lead to the psychopathic traits. In case of the extreme stress, either in childhood, adolescence or adulthood, the victim's personality could be profoundly disordered. Those clinicians (Courtois, Ford, Herman, Horowitz, Wilson, Zepinic, etc.) who have proposed complex posttraumatic stress disorder, had summarised its symptoms into the evident dysregulations: affects and impulses, attention or consciousness, self-perception, perception of the perpetrator, relations with others, somatisation and systems of meaning (Zepinic, 2012). Many of these symptoms overlap with the symptoms of psychopathic personality, supporting from a different point a departure of relationship between chronic trauma and personality disorders. Even more, some clinicians (Classen et al., 2006) proposed to speak of the new diagnoses - posttraumatic personality disorder-disorganised (PTSD-D), and posttraumatic personality disorder-organised (PTSD-O).

Studies about the phenomenon of dissociation with regard to trauma, specifically sexual abuse, have caused controversial results. Herman (1992) found that a majority of women (general patients not specifically diagnosed with the personality disorders) have experienced complete or partial amnesia for their sexual abuse at some time in the past. The overwhelming majority of these women were able to find some corroborating evidence of the sexual abuse and trauma suffered. In a study done by Briere and Conte (1993) of the sexual abuse in childhood, it was found that $54 \%$ of patients who reported sexual abuse memories mentioned having had some amnesia, partial or total, for the abuse between the time occurrence and age eighteen.

Different studies found a significant level of dissociation in severe personality disorders, often undiagnosed or misplaced with other symptoms. Ross (1989) suggests that among psychotic patients it was found that two thirds of them with borderline personality disorder met criteria for DSM criteria of dissociative disorder. The most dissociation has been related with traumatisation during childhood, as it was referred in Zanarini and colleagues research (2000). These findings are confusing in regard how such proportion of dissociation in the personality disorders were not diagnosed during initial assessment. The answer possible could be a fact that most standardised instruments to diagnose personality disorders do not include the items to evaluate dissociative symptoms and dissociative disorder. In studies aimed to determine the prevalence of dissociative disorders in general population, participants with a dissociative disorder present more frequently with the personality disorders than among other diagnosis or participants without a dissociative disorder. Needless to say, the evaluation of dissociative symptoms is quiet complex in particular using instruments to assess a general presence of the mental disorders.

Inspired by Janet, van der Hart et al. (2006) defined personality as the dynamic organisation within the individual of those biopsychosocial systems that determine characteristics of the mental and behavioural actions. One of the major such action system is defensive in nature and involve a variety of efforts to survive imminent threat to the integrity of the body and life (Zepinic, 2012). However, the most common dissociation is found in disintegrated self-structure (psychopathic personality) due to a severe traumatisation. Either due to insecure 
attachment or situation trauma, patient's personality becomes divided among two or more dissociative systems (Herman, 1992; Meloy, 1988; Patrick, 2006; van der Hart et al., 2006; Zepinic, 2017; Zuckerman, 2005) each mediated by particular action (sub)systems and each with its own first-person perspective. These dissociative parts, also known as dissociated self-states, are dysfunctional and inflexible in their actions and functions, and overly closed or contrary to each other.

In most patients with the disintegrated self-structure, this condition is strongly associated with the traumatic memories and patient's actions are re-enactment of the tendencies to defend against perceived or actual threat to the integrity of the body or to life itself, as well as the action tendencies regarding the needs for attachment and fear of the attachment loss (Zepinic, 2011, 2016). Thus, the person's mind is basically fixated into the traumatic memories that frequently involve frightening and frightened circumstances, but unreal. Such actions are mediated by the inner conflict drives of defence against threat and may be guided in particular by one of its subsystems: fight, flight, freeze, collapse, wound care, total submissions, or hypervigilance.

Depersonalisation and derealisation, as human experience, are nothing new-it has been viewed as the mind's natural "way of coping" with the overwhelmed shock or stress, or intolerable living conditions. As outcomes of being exposed to such pathological circumstances, the mind detaches itself from the surrounding for the purpose of survival (Zepinic, 2011). However, the depersonalisation may occur without any apparent trigger- "All is strange to me with no reason... I am outside my own body and individuality... I am detached, it is madness" -is a commonly reported by the patients who have experienced depersonalisation. Modern psychiatry and psychology see depersonalisation as a pervasive and distressing feeling of estrangement, known sometimes as the depersonalisation syndrome, may be defined as an affective disorder in which feelings of unreality and a loss of conviction of one's own identity and of a sense of identification with and control over one's own body are the principal symptoms. The unreality symptoms are of two kinds: a feeling of changed personality and a feeling that the outside world is unreal.

As an early trauma or insecure attachment represent cause for the development of pathological personality, it is common experience that the depersonalisation is a syndrome of the personality disorders, including psychopathy. However, it should be stated that not only childhood trauma, but also later severe stress (often seen in complex PTSD), or frightening episodes may precipitate the condition. Although there is no single accepted theory among the clinicians, most perceive depersonalisation as a defence against a variety of the negative feelings, conflicts, or experiences when the individual's more adaptive defence mechanisms fail. However, in many cases of the psychopathic personality, depersonalisation as a syndrome stays out of being assessed or it is mixed with the other symptoms (delusion, pathological obsession). Many studies revealed that such condition of the psychopathic personality, as well as psychopathy itself, stays unmasked and subsequently not treated.

Coid and colleagues (2009) in a representative sample of the UK population identified the prevalence of the personality disorders as $4.4 \%$, with men more likely to have a personality disorder (5.4\%) than women (3.4\%). However, most of the personality disorders are unlikely to be violent (except antisocial personality disorder and psychopathy with a high level of offences around $50 \%$ of the interviewed). It was found that people with the dramatic, erratic or emotional disorders, such as antisocial, borderline, and narcissistic personality disorder, were 10 times more likely to have some criminal conviction and eight times more likely to have spent time in prison. Also, compared with other mentally ill offenders, the personality disordered offenders are more likely to reoffend after being discharged from the hospital. Discharged patients with the personality disorders are seven times more likely to commit serious offences than other mentally ill offenders.

However, it must be noted that the studies focused on samples drawn from secure psychiatric settings likely represent those most severely ill and violent what could mislead to the clinical and the public bias about personality disordered individuals and criminality. Warren and colleagues (2003) conducted a study on female prisoners at a maximum-security prison in the USA. They identified 200 participants who met the criteria of the DSM Cluster B personality disorders which included antisocial, borderline, histrionic, and narcissistic personality disorder. The clinical interview was conducted with data from the prison files and self-reports to analyse offence information and behaviour in the prison. The authors reported that, of all participants with personality disorder, antisocial personality disorder was the largest ( 75 participants) followed by 47 with paranoid personality disorder, and 42 with borderline personality disorder.

They found that the comorbidity was common, with the antisocial personality disorder most commonly comorbid with the paranoid personality disorder, and the borderline personality disorder most commonly comorbid with the schizotypal personality disorder. The authors also assessed specific personality disorder clusters and individual personality disorders to reported violence, concluding "powerful relationship" between 
narcissistic personality disorder and violent behaviour. Those with narcissistic personality disorder were reportedly as being eight times more likely to have a current conviction for the violent offences (including homicide), and fewer times more likely to have a current conviction for the violent offences (excluding homicide). Narcissistic characteristic traits, which often overlaps with the psychopathy, of grandiosity and over-inflated self-confidence corresponds to the offenders' belief that violence is their only solution to solve their interpersonal problems.

Although study suggests that the personality disorder, in particular paranoid and narcissistic personality typologies which cover most symptoms found in psychopathy, are associated with a high level of the violence, the most studies focus on behaviour of participants whilst they were in prison and not on their offences within the community. As a result of the study, we supposed that the personality disorders (including psychopathy) may not have been present at the commission of the offences that led individuals to the charges and imprisonment. However, the study revealed that antisocial personality, if affected from a young age (what is common in psychopathy), of the certain enduring characteristics will continue in adulthood and that a role of antisocial personality (as well as psychopathy) disorder in the index offence should not be ruled out.

\subsection{Psychopathy - A Syndrome of Personality Disorders}

Subsequent to the controversies about violent and non-violent behaviours, many theorists have described psychopaths as the individuals "inside the mask" whose mind stays always busy-thinking about themselves. Psychopath is a master in manipulating others with no remorse or empathy for any damages caused by him. A long ago, Kohut (1971) stated that, in his clinical practice, the patients with psychopathic personality will usually explain problems that started back to their childhood, failure of empathy, and focus on the own self. He was of opinion that the most psychopathic personalities are caused by the failures in the patient's early development with unemphatic parents failing to mirror and supported, with their acceptance, the child's grandiosity, lack of empathy, selfishness, and improper relationships with the own self and the others. All of these pathological developments became brought unchanged into adulthood as "natural part of the psyche" with negatively toned evaluation of the own self. Certainly, everybody needs affirmation from other people; it is essential in maintaining psychic balance, relationships, self-value and self-confidence, keeping afloat in the world and helping to regulate our emotions and behaviours. However, pathological self-values lead to development of the disordered personality.

The features of the psychopathy, like in other personality disorders, usually become recognisable during the adolescence or early adult life in form of enduring patterns of thinking, affects, and behaviours - a disordered condition that is relatively stable over the time. Psychopathy in early childhood or adolescence appears to be persistent in particular maladaptive personality traits and will often persist unchanged into the adult life. The most feature of psychopathy, like in antisocial (dissocial) personality disorder or sociopathy, is a pervasive pattern of disregard for, and violation of, the rights of others (Hare, 2003).

The definition of antisocial personality disorder, many scientists consider as a basis to define the psychopathy. Like in psychopaths, the individuals with antisocial (asocial (Note 1)) personality disorder fail to conform to the social norms with respect to lawful behaviours and they may repeatedly perform acts that are grounds for the arrest, such as destroying property, harassing others, stealing, or pursuing illegal occupation. Individuals with these behavioural problems disregard the wishes, rights, or feelings of others - they are deceitful and manipulative in order to gain personal profit or pleasure. Persons with the antisocial personality disorder may repeatedly lie, con others, or malinger, and their impulsivity or inability to control impulses may be manifested by a failure to make valuable and achievable plan.

The individuals with antisocial personality disorder, like the psychopaths, are usually "persons of moment" action without forethought and without consideration for the consequences to self or others by their uncontrollable impulses and behaviours. They tend to be irritable and aggressive, and may repeatedly get into the physical fights or commit acts of physical assault. In essence, their aggressive behaviour is a reckless disregard for the safety of themselves or others. They usually fail in taking care or responsibility for others and often negligently put others under unnecessary risk. Kernberg (2003) described psychopath of having enraged, empty self, full of impotent anger at being frustrated, and fearful of the world which seems hateful and revengeful. Such patients are afraid of belonging to the ranks of the "mediocre" and anything average seems to them worthless and despicable, and psychopath shows quite antisocial personality (Kernberg, 2003).

Personality traits of the antisocial personality disorder are enduring patterns of perceiving, relating and thinking about the environment and oneself exhibited in a wide range of social and personal context (APA, 2013), and in case when personality traits are inflexible and maladaptive they cause significant dysfunction of a person. This is 
evident in one's impaired functioning from a normal or expected considering the individual's cognition, affects, and relationships. This is in particular when a person cannot control his inner or outer conflicts, or reacts in a manner that does not contribute to the problem solutions (Cooke et al., 1998; Zepinic, 2017). Maladaptive and inflexible approach is often a broad range of personal and social situations, and leads to clinically significant disturbances often tormenting person or causing impairment in social, occupational, or other important areas of functioning (APA, 2013). The pattern of maladaptation is commonly on long onset, less or more apparent and noticeable, but usually can be traced back at least early adolescence.

The diagnostic requirements for antisocial personality disorder, as well as for the psychopathy, involve an evaluation of the individual's long-term patterns if dysfunction, disordered personality, and sense of the own self. This could be, but not ultimately, distinguished from the personality dysfunctions or deviation in specific situation in which any other ordinary person would behave or react with some increased amount of reactivity (psychological or physiological). However, in such situations it is important to make distinction between emerge responses which differ in individuals with disordered and non-disordered personality. In order to make clarification, the clinicians should assess the stability of personality traits over time and across different situations that could cause distress or transient maladaptive affects or behaviours. Specific maladaptive personality often does not meet only one specific and recognised personality disorder but rather represents a syndrome of dysfunctional and incoherent personality.

The mutual characteristic between the psychopathy and antisocial personality disorder is that the individuals tend to be constantly and extremely irresponsible what can be indicated by significant short periods of employment at the same position, or abandonment of the job despite availability of the employment. Such individuals show no realistic plans at work place and they are repeatedly absent from work not explained by illness or other acceptable excuses. Financial irresponsibility is indicated by acts such as defaulting on debts, failing to provide support to the others, even to the loved ones. Individuals with antisocial personality disorder or psychopaths show little remorse for the consequences of their acts, or may be indifferent to, or provide a superficial rationalisation for, having hurt, mistreated, or think that "life is not fair". They usually blame others for own failures and see others foolish, helpless, or deserving what they received, but minimise their negative consequences upon others due to their actions or impose total indifference. Hare (1970) described social deviance in the psychopathy: impulsivity, poor behaviour control, need for excitement, lack of responsibility, and adult antisocial behaviours.

Clinicians proposed that the psychopaths are inherently fearless and that their fear deficit interferes their relationships with others and an inability to inhibit properly. They often do not show remorse to punish others or behave violently/aggressively and, at the same time, do not show fear or anxiety for the eventual consequences even legal action taken against their improper behaviours. They respond in passive-avoidant way and do not accept eventual responsibility for doing something hurtful or wrong to someone and will rather find the other's mistake or wrong doing/responding. Psychopaths display poor fear conditioning and minimal or not at all automatic arousal (shaking, sweating, heart palpitations, breathlessness, etc.) while doing something wrong such as the violent or aggressive behaviour. They will not show anticipation of aversive events such as loud sounds or electric shock, but will show extreme reactivity if their response is rejected or ignored by others (Zepinic, 2017).

The total pattern of the psychopath's personality differentiates him from the normal population. His aggression is more intense, his impulsivity is more pronounced, his emotional reactions are more shallowed. Psychopath is a chronically unstable and aimless lifestyle marked by casual and flagrant violations of the social norms and expectations (Cooke et al., 1998; Hare, 1970; Hare, 1999). Two features dominate -one depicting feelings and relationships, the other social deviance- provide a comprehensive picture of the psychopathic personality.

Psychopath is unlikely to spend much time weighing pros and cons of the course of an action or considering the possible consequence simple because of his arrogance and grandiose self-image. More than display the psychopath's temper, impulsivity and aggressiveness are often result from an aim that plays central role in the most of the psychopath's behaviours - to achieve immediate satisfaction, pleasure, escape or relief. He is absorbed in own needs and grandiosity, vehemently demanding satisfaction. He is not able to postpone pleasure and his inner force to satisfy his grandiose self-image regardless of any circumstances or restrictions in the environment. It seems that psychopaths never learn from the past—-their intentions are "here-and-now" driven and they ignore needs of others.

Besides being impulsive, the psychopath is likely reactive to perceive insults with no inhibitory control over his behaviour. Normal individuals have powerful inhibitory controls and, even if they would like to respond aggressively, they usually able to keep their aggression under control. On the other hand, with psychopaths these 
inhibitory controls are weak, and the slightest provocation may cause eruption of the volcano of aggression. As a result, the psychopath is short-tempered or hot-headed and tends to respond to frustration, failure, discipline, and criticism in quite aggressive ways with sudden violence, threats, and verbal abuse. The psychopaths take offence easily and become angry and aggressive over trivialities, and often in a context that appears inappropriate to others (Hare, 2003).

However, their outbursts even quite extreme are short-lived, and they quickly resume acting as if nothing happened out of their ordinary behaviour. Immediately after the hanging up their aggressive and abusive behaviours, they began to laugh and joke with others and seem genuinely unaware of their severe aggression, verbal abuse or threatening behaviour. It is not unusual for the psychopaths to inflict serious physical or emotional damages upon others and then refuse to acknowledge that they have a problem controlling their temper. In most cases, the psychopaths see their aggressive behaviour as a natural response to someone's unreasonable provocation (Zepinic, 2017).

Psychopaths have an ongoing and excessive needs for excitement what in most cases result in breaking the rules. Cleckley (1941) explained that the psychopaths are unable to tolerate the self-containment required by the ordinary rules finding that rules are degrading, insulting, or even physically threatening to the psychopath's personality. Some psychopaths may use a wide range variety of drugs or alcohol in order to achieve excitement, or they move often from place to place, changes jobs quite frequently - in general they are unstable in all areas of their life. Many psychopaths, who are frequent criminal offenders, would report that they do crime for the excitement or thrills, or even do some dangerous things just for their fun regardless of the consequences and damages caused. Even some psychopathic criminals will report that escaping from the prison is not because of freedom but for a certain excitement knowing that searching for them will be so alarming. Clinicians are of opinion that such excitement is the psychopath's inability to tolerate routine or monotony - psychopaths become easily bored. It is very rare to find the psychopaths engaged in the occupations or activities that are repetitive, or that require intense concentration over long periods of time.

Commitments, obligations, and responsibility mean nothing to the psychopaths-irresponsibility and unreliability extends to every part of their lives. Usually their performances on the job is erratic, with frequent absences or finished duties out of time, they misuse company resources, violate company policy, and generally show untrustworthiness. Psychopaths very likely honour formal or implied commitments to the others, in particular to the authorities, organisations or common principles. They do not hesitate to misuse or abuse any resources and do not care if they disappoint or induce damages to close friends or family members by their action - they are not deterred by the possibility causing hardship or risk others. Hare (2003) described that in many clinical cases the HIV positive psychopaths have continued to have unprotected sex with the healthy, unsuspected partners despite knowing how risky it is. They carried little about the horrendous implications of their irresponsible behaviour.

Theorists and clinicians (Allport, 1961; Benjamin, 2003; Hakkanen-Nyholm \& Nyholm, 2012; Meloy, 1988; Sarkar \& Adshead, 2006; Schore, 2003; Zepinic, 2017) stated that human psychopathology should be seen as an aftermath of inner conflicts and the person's inability to control power of their drives. Without the sense of inner freedom and autonomy of the ego there would be no individuation or independency, neither would be fully controlled actions, nor meaning. Bearing these in mind, the individuals who are driven by the inner conflicts drive -commonly evident in psychopathy- have no conscience nor responsibility for their behaviours. Confrontation with the one's own darkness without an alert conscience makes limited awareness of what is right and what is wrong. This is a psychic reality in everyone's life and power to control the inner conflict drives belong to wholeness, and the goal of individuation is not a perfect person but complete individual with bad and good meanings. The individual may straggle through self-awareness, and through confronting to the inner conflict drives which hold the destructive forces within the person.

Psychopaths usually fail to compensate for their wrong-doing or make the amends for their bad behaviours. Like those with antisocial personality disorder, they frequently lack of empathy and tend to be callous, cynical, and contemptuous of the feelings, rights, and suffering of others (APA, 2013). Psychopaths are characterised by displaying superficial charm and can be quite voluble and verbally eloquent to impress others who are not familiar with particular topic. Lack of empathy, inflated self-appraisal, and superficial charm are features that have been commonly included in traditional conceptions of psychopathy that may particularly distinguishing of the disorder and more predictive of recidivism in prison or forensic settings, where the criminal or aggressive acts are likely to be non-specific. These individuals may also be irresponsible and exploitative in their relationships and rare sustain a long-existing relationship. They may also experience dysphoria, including complaints of tension, inability to tolerate boredom, and depressed mood. Psychopathy is a chronic condition 
and may be less evident or remit when the individual grows older and tends to be particularly evident with respect to engaging in the criminal behaviours, drugs abuse, and antisocial behaviour (Zepinic, 2017).

Individual with narcissistic personality disorder in its criteria contains some characteristics that are common in psychopathy: pervasive pattern or grandiosity (grandiose sense of self-importance, preoccupied with fantasies of unlimited success, power, brilliance), lack of empathy, beliefs that he is "one special and unique" and can only be understood by high-status people or institutions, shows arrogance, naughty behaviours or attitudes, he is the interpersonally exploitative. The essential diagnostic features of the narcissistic personality are a pervasive pattern of grandiosity, needs for admiration, and lack of empathy that begins in early adulthood and is present in a variety of context (APA, 2013).

Diagnostic features for narcissism described in DSM-5 (APA, 2013) are similar what Hare (1970) evaluated in describing the emotional and interpersonal symptoms of the psychopathy: glib and superficial, shallow emotions, egocentric and grandiose, lack of remorse or guilt, lack of empathy, deceitful and manipulative. The main criterion for the narcissistic personality disorder individual is grandiose sense of self-importance and person routinely overestimates his "special" abilities and inflates his accomplishments, often appearing pretentious. Narcissist often implicit in the inflated judgments of his own accomplishments is a common underestimation (devaluation) of the contribution of the others. Individuals with narcissistic personality disorder are often preoccupied with the fantasies of unlimited success, power, beauty, or ideal love. The narcissists may ruminate about the "long-overdue" admiration and privilege, and compare themselves favourable with famous or privileged people - egocentric and grandiose (Hare, 1970).

Like psychopaths, the individuals with narcissistic personality disorder believe they are superior or unique and expect from others to recognise it. Their self-esteem is enhanced (mirrored) by the idealised value that they assign to those with whom they associate. Such individuals are preoccupied with how well they are doing, and how favourably they are regarded by others and generally require excessive admiration although their self is very fragile. This often takes them constantly searching for the attention and admiration, and compliments despite lack of reasons for that. A sense of entitlement is evident in these unreasonable expectations, especially for the favourable treatment. The sense of entitlement, combined with a lack of sensitivity to the wants and needs of others, may result in the conscious or unwitting exploitation of others - they expect to be given whatever they want or feel they need, no matter what it might mean to others (APA, 2013). Those related to the narcissist, like to the psychopath, typically find an emotional coldness and lack of the reciprocal interest as they harshly devaluate any contribution or achievement by others, in particular when others have received acknowledgment or prise for their accomplishments.

Despite to all grandiosity and self-focus, psychopathic personality in essence has a fragile self which needs become extreme: other people are treated greedily, exploitatively, not like other human beings, but like the objects in the service of only fullfeeding the psychopath's grandiosity. The psychopath's grandiosity usually takes pathological defence through the special relationship with those individuals who express admiration and blind loyalty to the psychopath. Thus, like those with narcissistic personality, the psychopath feels hurt if not being treated in the way he feels he deserves to be treated. In fact, despite bubbling and charming approach towards others, the psychopath is isolated from others into his grandiose self unable to achieve a satisfying intimacy with anyone. On an emotional roller coaster, he is a subject to abrupt shifts in mood oscillating from excitement and elevation when in his grandiose state being better than anyone else, only to collide with reality downward into a deflated and fragile self. While treating psychopath, it is evident that clinician deals with one's "exaggerated love of self" combined with a "devaluation of others". This grandiosity exists paradoxically alongside the self-fragility - psychopaths are prone to feeling rejected and easily hurt (Babiak \& Hare, 2006; Hakkanen-Nyholm \& Nyholm, 2012).

All the psychopath's self-love means an impoverishment of his interior world and relationship with significant others - some sense of "specialness". Love relationships are usually fleeting, superficial with a little capacity for empathy and with no genuine attachment. The relationship is commonly short-lived as "no-one can give attention" what the psychopath "deserves". The psychopath's thirst for the admiration and fragile self is hidden behind feelings of disappointment, passive aggressive resentment or even rage directed towards others failing to fulfil his (unreasonable) needs and demands. Beneath the surface of charm, in contrast, the psychopath has little real interest in others, disregarding them, and only idealising them when they are a source of his grandiose self supply (Kernberg, 2003).

The greediness and demandingness could make psychopath quite aggressive or callous in his grandiose demands finding that destruction of others is actually a moral act. Someone who is aggressive in order to satisfy his 
grandiose self is hardly focused on the importance of developing guilt and concern or empathy for the others. Kernberg (2003) found it is quite difficult to treat psychopaths because their grandiosity cannot tolerate any meaningful interpretations as they feel them to be injuriously critical and degrading, instead of admiring. Because of their disappointment about the therapy progress, the psychopaths usually leave therapy before any real personality changes are achieved.

\section{Discussion}

As pathological personality is the complex phenomena, usually with disintegration of the person's wholeness, any full understanding of psychopathy needs to consider aetiology of genetics, neurobiological vulnerability combined with childhood trauma that led to dysregulated emotions, distorted cognition, social skills deficits, and often dissociated coping strategies. We understand that the psychopathy steaming from combination of the trauma factors and the biological factors. In the most extreme cases, the psychopathy represents comorbid personality often combined with the dissociative disorder. Psychopaths with symptoms of dissociation usually have a long history of childhood traumatisation, and their personality symptoms are at the level of a split consciousness run by the inner drives of the traumatic memories (van der Hart et al., 2006; Zepinic, 2016).

Among many theorists and clinicians, the puzzling question while treating the psychopaths is related how, in fact, define the problem being treated: as a simple disorder or syndromal condition combined of different symptoms of personality disorders. As it was stated earlier, this jigsaw is still divides clinicians in their approach towards the psychopathy — is it a simple mental illness or a syndrome of the disordered personalities? Comorbidity of the psychopathy is quite confusing considering many interrelated features that can lead to conclude one particular diagnosis of the mental illness or the multiple disorders. In many clinical examples, there is overlap in symptoms that lead clinicians to diagnose psychopaths of having personality disorders with the satisfactory diagnostic criteria. In order to more precisely clarify this puzzle, we should review diagnostic criteria for the personality disorders and symptoms of some personality disorders that overlap with the symptoms of psychopathy.

In essence, personality disorder describes an individual who does not experience hallucinations or delusions characterised in psychosis, however has serious and lasting impairment in behaviour, cognitive, and emotional relationships with others. In most personality disorders, particularly in psychopathy, there are common presence of (1) grandiose sense of self-importance, (2) beliefs that he is "special and unique" and can only be understood by other special or high-status people, (3) preoccupation with fantasies of unlimited success, power, brilliance, or ideal love, (4) baseless requirement of excessive admiration, (5) interpersonally exploitive taking advantages of others with no remorse or empathy, (6) unwilling (uninterested) to recognise or identify with the feelings or needs of others, and (7) demonstration of arrogance and ignorance toward the others (Zepinic, 2017).

The DSM-5 (APA, 2013) recognised eleven different types of personality disorders with their particular nosology, aetiology and symptomatology, and all of them can be related or overlap with the condition of the psychopathy. Personality is a set of relatively stable, predictable, and ego-syntonic habits that characterised the person in his way of managing day-to-day living: when these habits are enough beyond the normal range to warrant the appellation of personality disorder is difficult to define, and often the label is more a social diagnosis of the non-conformity than designation of a disease process in the usual sense (Campbell, 1996). By definition, personality disorder is an enduring pattern of the inner experiences (affects, thoughts, impulses) and behaviours that deviates markedly from the expectations of the individual's culture, is pervasive and inflexible, has an onset in adolescence or early childhood, is stable over time, and leads to distress or impairment (APA, 2013). Although not being included in DSM-5 diagnostic criteria, this general definition of the personality disorder covers, in essence, the most problems that appear in psychopathy.

Most clinicians are of opinion that psychopathy can often be considered as the combination of paranoid, schizoid, antisocial, narcissistic, and borderline personality disorders. However, the most cited in the research and clinical practice is a psychopathy combined of antisocial and narcissistic personality. Considering DSM- 5 diagnostic clusters based on descriptive similarities, it seems that psychopathy is syndromal disorder of Cluster B which includes antisocial, borderline, histrionic, and narcissistic personality disorders. Admitting this diagnostic approach, it confirms that psychopathy is a qualitatively distinct clinical syndrome which personality traits are enduring patterns of the perceiving, relating to, and thinking about the environment and oneself that are in a wide range of instability (Zepinic, 2017).

The psychopath's personality traits are inflexible and maladaptive causing significant functional impairments (social, cognitive, and emotional) and interpersonal distress. The essential features of psychopathy are an enduring pattern of the inner conflicts, the emotions and behaviours that deviate markedly the psychopath's self-representation in the areas of his affectivity, interpersonal functioning, and impulse control (Zepinic, 2017). 
These enduring patterns are inflexible and pervasive across a broad range of the personal and social situations, and lead to a clinically significant distress or impairment in social, occupational, or other important areas of psychopath's functioning. The patterns are usually stable and long-existing, and they can be traced back to the early childhood or adolescence.

Like with diagnosis of personality disorders in DSM-5 (APA, 2013), the diagnosis of psychopathy as the syndromal condition requires an evaluation of the individual's long-term patterns of dysfunction, and the particular personality features should be evident before the adulthood. The clinicians should assess the stability of the condition over time and across different situations. In evaluating psychopathy, in particular successful or non-criminal psychopath, some collateral information about psychopath's behaviours and relations could be more supportive to make clear picture of the disorder than the results from clinical interview or psychometric testing. Often the assessment of psychopathy is complicated by the psychopath's ability to skilfully hide his emotions and the inner conflict power in form of charming behaviour and hard-working attitudes.

\section{References}

Allport, G. W. (1961). Pattern and growth of personality. Holt \& Co., New York.

American Psychiatric Association. (2013). Diagnostic and Statistical Manual of Mental Disorders (5th ed.). APA, Arlington.

Babiak, P., \& Hare, R. D. (2006). Snake in suits: When psychopaths go to work. Harper Collins, New York.

Babiak, P., Neumann, C. S., \& Hare, R. D. (2010). Corporate Psychopathy: Talking the walk. Behavioural Science and the Law, 28, 174-193. https://doi.org/10.1002/bsl.925

Battle, C. L. et al. (2004). Childhood maltreatment associated with adult personality disorders: Findings for the Collaborative Longitudinal Personality Disorders Study. Journal of Personality Disorders, 18, 193-211. https://doi.org/10.1521/pedi.18.2.193.32777

Benjamin, L. S. (2003). Interpersonal Diagnosis and Treatment of Personality Disorders. New York, Guilford Press.

Black, D. W., \& Larsen, L. C. (1999). Bad boys, Bad men: Confronting Antisocial Personality Disorder. New York: Oxford University Press.

Briere, J., \& Conte, J. (1993). Self-reported amnesia in adults molested as children. Journal of Traumatic Studies, 6, 21-31. https://doi.org/10.1002/jts.2490060104

Campbell, R. J. (1996). Psychiatric Dictionary (7th ed.). New York: Oxford University Press.

Classen, C., Pain, C., Field, N., \& Woods, P. (2006). Posttraumatic stress disorder: A reformulation of the complex posttraumatic stress disorder and borderline personality disorder. Psychiatric Clinic of North America, 29, 87-112. https://doi.org/10.1016/j.psc.2005.11.001

Cleckley, H. C. (1941). The Mask of Sanity. Mosby, St. Luis.

Coid, J., Yang, M., Ulrich, S., Roberts, A., \& Hare, R. D. (2009). Prevalence and correlates of psychopathic traits in the household population of Great Britain. International Journal of Law and Psychiatry, 32, 65-73. https://doi.org/10.1016/j.ijlp.2009.01.002

Cooke, D. J., Forth, A. E., \& Hare, R. D. (1998). Psychopathy: Theory, research, and implication for society. Kluwer, Dordrecht. https://doi.org/10.1007/978-94-011-3965-6

Gao, Y., \& Raine, A. (2010). Successful and Unsuccessful Psychopaths: A Neurobiological Model. Behavioural Science and Law, 28, 194-210. https://doi.org/10.1002/bsl.924

Hakkanen-Nyholm, H., \& Nyholm, J. O. (2012). Psychopathy and Law. Wiley-Blackwell, London. https://doi.org/10.1002/9781119944980

Hare, R. D. (1970). Psychopathy: Theory and Research. John Wiley \& Sons, New York.

Hare, R. D. (1999). Psychopathy as a risk factor for violence. Psychiatric Quarterly, 3, 181-197. https://doi.org/10.1023/A:1022094925150

Hare, R. D. (2003). Manual for Psychopathic Checklist—Revised (2nd ed.). Multi-health System, Toronto.

Herman, J. (1992). Trauma and Recovery. Basic Books, New York.

Kernberg, O. F. (2003). The psychotherapeutic management of psychopathic, narcissistic, and paranoid transference. In T. Millon et al. (Eds.), Psychopathy. New York: Guilford Press. 
Kohut, H. (1971). The Analysis of the Self. New York: International University Press.

Meloy, J. R. (1988). The Psychopathic mind: Origins, dynamics, and treatment. Jason Aronson, New York.

Newman, J. P., \& Kosson, D. S. (1986). Passive avoidance learning in psychopathic and non-psychopathic offenders. Journal of Abnormal Psychology, 95, 257-263. https://doi.org/10.1037/0021-843X.95.3.252

Patrick, C. J. (2006). Handbook of Psychopathy. New York: Guilford Press.

Porter, S., Brinke, I., \& Wilson, K. (2009). Crime Profiles and conditional performance of psychopathic and non-psychopathic sexual offenders. Legal and Criminological Psychology, 14, 109-118. https://doi.org/10.1348/135532508X284310

Raine, A. (2013). The Anatomy of Violence: The Biological Roots of Crime. Pantheon, New York.

Ross, C. A. (1989). Multiple Personality Disorder. John Wiley \& Sons, New York.

Sarkar, J., \& Adshead, G. (2006). Personality disorders as disorganisation of attachment and affect regulation. Advances in Psychiatric Treatment, 12, 297-305. https://doi.org/10.1192/apt.12.4.297

Schore, A. N. (2003). Affect Dysregulation and Disorders of the Self. WW Norton, New York.

Van der Hart, O., Nijenhuis, E., \& Steel, K. (2006). The Haunted Self. WW Norton, New York.

Van der Kolk, B. A., McFairlane, A. C., \& Weiseath, L. (1996). Traumatic Stress. New York: Guilford Press.

Warren, J. L. et al. (2003). Psychopathy in women: Structural modelling and co-morbidity. International Journal of Law and Psychiatry, 26(3), 223-242. https://doi.org/10.1016/S0160-2527(03)00034-7

Zanarini, M. C. et al. (2000). Risk factors associated with the dissociative experiences of borderline patients. Journal of Nervous Mental Disorders, 188, 26-30. https://doi.org/10.1097/00005053-200001000-00005

Zepinic, V. (2011). Hidden Scars: Understanding and Treating Complex Trauma. Xlibris, London.

Zepinic, V. (2012). The Self and Complex Trauma. Xlibris, Bloomington.

Zepinic, V. (2016). Disintegration of the Self-Structure Caused by Severe Trauma. Psychology and Behavioural Science, 5, 83-92. https://doi.org/10.11648/j.pbs.20160504.12

Zepinic, V. (2017). Psychopathy: Guilty Mind or Guilty Brain. Xlibris, Bloomington.

Zepinic, V. (2017a). Posttraumatic Stress Disorder in the Courtroom: Insanity Defence. American Journal of Applied Psychology, 6, 22-30.

Zuckerman, M. (2005). Psychobiology of Personality (2nd ed.). New York: Cambridge University Press. https://doi.org/10.1017/CBO9780511813733

\section{Note}

Note 1 . Asocial personality disorder is defined in ICD-10 diagnostic criteria with similar symptoms described in DSM-5 diagnostic criteria for antisocial personality disorder.

\section{Copyrights}

Copyright for this article is retained by the author(s), with first publication rights granted to the journal.

This is an open-access article distributed under the terms and conditions of the Creative Commons Attribution license (http://creativecommons.org/licenses/by/4.0/). 